\title{
Química de igarapés de água preta do nordeste do Amazonas - Brasil
}

\author{
Adriana Maria Coimbra HORBE ${ }^{1}$, Liliam Gleicy de Souza OLIVEIRA
}

RESUMO

Neste estudo foram analisados $\mathrm{pH}$, Eh, condutividade elétrica, cloreto, sílica, fosfato, $\mathrm{K}, \mathrm{Na}, \mathrm{Ca}, \mathrm{Mg}, \mathrm{Fe}, \mathrm{F}, \mathrm{Zn}, \mathrm{Ni}, \mathrm{Co}, \mathrm{Mn}, \mathrm{Pb}$, $\mathrm{Cu}, \mathrm{Cr}$, Li e Cd nas águas de drenagens de pequeno porte no nordeste do Amazonas. As águas são pretas, predominantemente ácidas e levemente redutoras e com baixo conteúdo de elementos dissolvidos. Contudo, a química indica que são heterogêneas e refletem o ambiente geológico por onde percolam. $\mathrm{SiO}_{2}, \mathrm{Na}$ e $\mathrm{K}$ são os constituintes mais abundantes na fase dissolvida, especialmente nas drenagens mais a norte pertencentes as bacias do Uatumã, Urubu e no igarapé Canoas que drenam as rochas da Suíte Intrusiva Água Branca e Mapuera e as sedimentares do Grupo Iricoumé e as Formações Prosperança, Nhamundá, Manacapuru, Pitinga Os igarapés menores, que drenam exclusivamente os sedimentos da Formação Alter do Chão, são os mais diluídos. Os elementos-traços analisados estão em concentrações muito baixas.

PALAVRAS CHAVE: afluentes do Amazonas, estiagem; carga dissolvida

\section{Chemical composition of black water creeks from northern of Amazonas - Brasil}

ABSTRACT

The present study analyzed $\mathrm{pH}$, Eh, electric conductivity, chloride, silica, phosphate, $\mathrm{K}, \mathrm{Na}, \mathrm{Ca}, \mathrm{Mg}, \mathrm{Fe}, \mathrm{Zn}, \mathrm{Ni}, \mathrm{Co}, \mathrm{Mn}, \mathrm{Pb}$, $\mathrm{Cu}, \mathrm{Cr}, \mathrm{Li}$ and $\mathrm{Cd}$ in draining waters making part of smaller creeks located in the northeastern Amazonas State. The waters have black colour, are predominantly acid and slightly reductive and have low content in dissolved elements. Otherwise they are chemically heterogeneous and reflect the geological environment. The $\mathrm{SiO}_{2}, \mathrm{Na}$ and $\mathrm{K}$ are the most abundant dissolved constituents, especially on the drainages farther north belonging to Uatumã, Urubu basins and Canoas Stream, which drain the rocks of Água Branca and Mapuera Intrusive Suite, Iricoumé Group and Prosperança, Nhamundá, Manacapuru, Pitinga Formations. Smaller Streams, which drains Alter do Chão Formation sediments, exclusively, are the most diluted ones. The analysed trace elements present very low concentrations.

KEYWORDS: tributaries from Amazonas River; dry season; dissolved load

1 Universidade Federal do Amazonas - UFAM, ahorbe@ufam.edu.br 


\section{INTRODUÇÃO}

A maioria dos rios de pequeno porte da Amazônia, classificados como de cor preta, nascem nos escudos das Guianas e do Brasil Central ou nas rochas sedimentares cretáceas da bacia Amazônica. Nesses ambientes o processo de erosão é reduzido pela mata pluvial, conseqüentemente a carga de sedimentos é baixa e os rios são transparentes. A cor escura das águas é devido à presença de material orgânico solúvel de coloração marrom ou avermelhada (ácidos húmicos e fúlvicos) produzido pela decomposição da floresta ao ser inundada parte do ano (Sioli, 1965).

As pesquisas realizadas no mais conhecido rio de águas pretas em volume da Amazônia, o Negro, descrevem suas águas como levemente ácidas e de baixa condutividade elétrica, o que reflete a pobreza em elementos alcalinos e alcalinoterrosos e nutrientes como fósforo livre, nitrito e nitrato (Lopes, 1992). Cunha e Simōes (2000) verificaram que as suas águas, nas proximidades de São Gabriel da Cachoeira, são ácidas, com teor baixo em cátions dissolvidos, e atribuem estas características à contribuição geoquímica dos terrenos arenosos presentes na regiáo das montantes do rio Negro. Em geral, as águas pretas têm mais ferro e alumínio que as brancas; dentre os álcalis, apesar de $\mathrm{Na}, \mathrm{Ke} \mathrm{Ca}$ terem grande variação de teores, os dois primeiros são normalmente mais elevados e o Mg é mais baixo (Tab. 1) (Sioli, 1957; Santos et al., 1984; Santos e Ribeiro, 1988; Konhauser et al., 1994; Gaillardet et al., 1997, entre outros). Em igarapés naturais próximos a Manaus, $\mathrm{SiO}_{2}$ é mais elevado que $\mathrm{Cl}$ e, dentre os álcalis, $\mathrm{Na}$ predomina sobre $\mathrm{K}$ e Ca e $\mathrm{Mg}$ são os mais baixos (Silva et al., 1999, Horbe et al., 2005).

Para ampliar o estudo de pequenas drenagens na região nordeste do Amazonas, foram selecionados igarapés que fazem parte das bacias do Uatumã e Urubu e alguns tributários do rio Amazonas e Negro. Foi utilizada como logística de acesso para amostragem as principais rodovias da região (BR-174, AM010, AM-240 e AM-363) (Figura 1). Como algumas destas drenagens já foram objeto de estudos anteriores (Schmidt, 1972 e Campos, 1994), os dados deste trabalho permitiram verificar se ocorreram modificações na composição química de suas águas ao longo dos anos, além de possibilitar o estudo comparativo com as águas do rio Negro e verificar, neste caso, as influências de distintos meios geológicos.

\section{ASPECTOS FISIOGRÁFICOS E GEOLÓGICOS}

O clima da região é do tipo equatorial, quente e úmido com temperatura média em torno de $26^{\circ} \mathrm{C}$, com períodos de cheia nos meses de dezembro a junho e de estiagem para os demais meses do ano. A umidade relativa do ar varia em torno de $80 \%$ e a média de precipitação pluviométrica anual é acima $2.000 \mathrm{~mm} / \mathrm{ano}$ (Nimer, 1991).
O relevo da região, marcado por interflúvios tabulares, colinas e vales, abrange o Planalto Dissecado Rio Trombetas - Rio Negro e o Planalto da Bacia Sedimentar do Amazonas, segundo a classificação do Radambrasil (1978). A cobertura vegetal é de floresta densa, ocorrendo também contato com campinarana. Edafologicamente, Latossolo Amarelo é a tipologia predominante, com solos Hidromórficos Gleyzados nas áreas de planície.

A região de estudo abrange as seguintes unidades geológicas (das mais antigas para as mais jovens): Suítes Intrusivas Água Branca e Mapuera, Grupo Iricoumé e Formaçóes Prosperança, Nhamundá, Manacapuru, Pitinga e Alter do Chão (Santos et al., 1974; Veiga et al., 1979; Schobbenhaus et al., 1984; Cunha et al., 1984 e Valério et al., 2006) (Figura 1). As rochas das Suítes Intrusivas Água Branca e Mapuera e do Grupo Iricoumé são compostas por granitóides (monzogranitos, granodioritos e dioritos), vulcânicas e piroclásticas ácidas e intermediárias. No seu conjunto apresentam composição mineralógica a base de quartzo, feldspato potássico, plagioclásio, anfibólio, biotita, quartzo, feldspato, piroxênio em menor proporção apatita, opacos, clorita e epidoto (Valério et al. 2006). As Formaçōes Prosperança, Nhamundá, Pitinga, Manacapuru e Alter do Chão são constituídas por arcóseos, arenitos silicificados, arenitos argilosos, conglomerados e folhelhos (Cunha et al., 1984). Mineralogicamente, estas rochas são constituídas essencialmente por quartzo e caulinita e em menor proporção por feldspato.

O rio Uatumã, a maior drenagem da região estudada, tem suas nascentes na porção a norte da área, em domínios sob a influência de rochas ígneas das Suítes Intrusivas Água Branca e Mapuera e do Grupo Iricoumé (Figura 1). Devido a dificuldade de acesso a estes terrenos, somente foram amostrados seus dois afluentes maiores, os igarapés Coruja

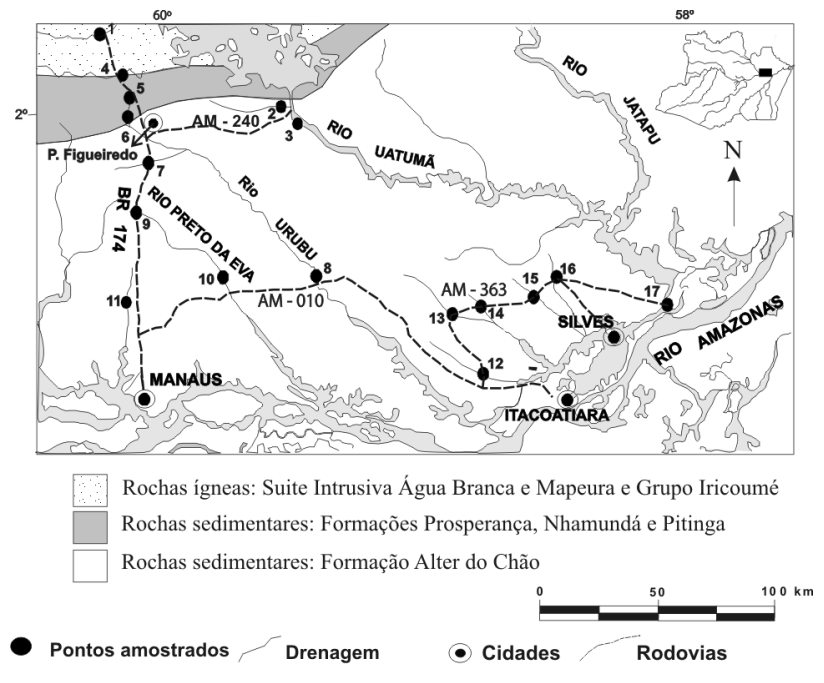

Figura 1 - Mapa de localização dos pontos amostrados e geologia da área 
(P1) e Barreto (P2), localizados ao longo da BR-174, além de um ponto $10 \mathrm{Km}$ a jusante da hidroelétrica de Balbina (P3). Ainda nos tratos norte da área estudada sob influência do mesmo ambiente geológico, também foi amostrado o igarapé Canoas (P4), afluente do rio Cuieiras, que é tributário da margem esquerda do rio Negro.

O rio Urubu, segunda drenagem em extensão na área, tem suas cabeceiras na porção norte da regiáo estudada ( $\mathrm{P} 5$, P6 e P7 - Figura 1), sob influência de rochas sedimentares das Formaçōes Prosperança, Nhamundá, Manacapuru e Pitinga, e drena a Formação Alter do Chão no seu amplo segmento médio e jusante. Na porção sul-sudeste da região, dentre as drenagens de menor porte, tem destaque o rio Preto da Eva (P9 - denominado no local de amostragem de igarapé Preto - e P10), o igarapé Tarumã-Açú (P11) e os igarapés dos pontos 12 a 17 na porção sul-sudeste da área, todos percolam exclusivamente os sedimentos da Formação Alter do Chão e foram denominados neste trabalho de rios menores (Figura 1).

\section{MATERIAIS E MÉTODOS}

As amostras de água foram coletadas em novembro de 2002, no final do período da estiagem, sendo tomadas a uma profundidade de $10 \mathrm{~cm}$ da lâmina de água. Após sucessivas lavagens com água da drenagem a ser amostrada, foram armazenadas em recipientes de polietileno com capacidade para $2000 \mathrm{~mL}$. Estes foram previamente desmineralizados com solução de ácido nítrico a $25 \%$, lavadas com água deionizada e secas. Ao todo foram coletadas 17 amostras ao longo das rodovias BR-174, AM-010, AM-240 e AM-363 (Figura 1) que correspondem a águas de cor preta.

No local de amostragem foram medidos $\mathrm{pH}$, Eh e condutividade elétrica por potenciometria e, em seguida, as amostras foram preservadas sob refrigeração $\left(4^{\circ} \mathrm{C}\right)$ para evitar alteração das suas propriedades originais. No Laboratório de Geoquímica da UFAM, as amostras foram filtradas à vácuo com filtro de fibra de vidro GF/C (Whatman), para a determinação de cloreto, fosfato, sílica, flúor e metais $(\mathrm{K}, \mathrm{Na}$, $\mathrm{Ca}, \mathrm{Mg}, \mathrm{Fe}, \mathrm{Zn}, \mathrm{Ni}, \mathrm{Co}, \mathrm{Mn}, \mathrm{Pb}, \mathrm{Cu}, \mathrm{Cr}, \mathrm{Li}, \mathrm{Cd}, \mathrm{Sr}$ e Mo). O cloreto foi determinado por titulação; fosfato e sílica por espectrofotometria ótica; flúor, por íon específico; os metais por espectrometria de absorção atômica com chama, segundo as especificaçōes do Standard Method (1998).

Os resultados foram submetidos à análise estatística multivariada por componentes principais (Statística 5.1), com o objetivo de reduzir os parâmetros analisados (variáveis) e as amostras a um conjunto mais significativo. Esta técnica, que possibilita avaliar a inter-relação existente entre as variáveis (parâmetros) e as amostras, gera fatores e escores que representam a variância dos dados, ou seja, o grau de correlação ou significância. A análise multivariada abrangeu duas etapas: na primeira, obtiveram-se os escores de todas as variáveis; posteriormente, foram selecionadas aquelas que tiveram variança maior que $0,7 \mathrm{em}$ um dos dois primeiros fatores. Com base nessas variáveis foram determinados os escores das amostras também nos dois primeiros fatores. Esses escores foram representados em gráfico para melhor visualização.

\section{RESULTADOS E DISCUSSÃO}

Os valores obtidos para $\mathrm{pH}$ variaram entre 4,44 e 6,21, os mais baixos foram no rio Urubu $(4,44)$ e nos igarapés Urubuí $(4,54)$ e Barreto $(4,76)$ e o mais elevado (menos ácido) no igarapé Canoas $(6,21)$. O Eh (potencial de oxi-redução) variou, em média, entre $206 \mathrm{mV}$ à $272 \mathrm{mV}$ e apresentou relação inversa com o $\mathrm{pH}$, ou seja, quanto menos ácida a água, mais oxidante ela é (Tabela 1, figura 2). A relação entre $\mathrm{pH}$ e Eh indica que o ambiente é redutor ácido e, apesar do igarapé Canoas ser o menos ácido, constata-se regionalmente uma tendência de diminuição de acidez para sul-sudeste, à medida que as bacias de drenagens diminuem sua área de escoamento e passam a serem influenciadas exclusivamente pela Formação Alter do Chão (Figura 2).

Dentre os álcalis, $\mathrm{K}$ e $\mathrm{Na}$ predominam na maioria das drenagens, especialmente nos igarapés Canoas e Coruja, sendo os valores de $\mathrm{K}$ bem mais elevados que os de $\mathrm{Na}$. Os demais igarapés têm variações menos acentuadas no conteúdo de álcalis e os mais a sudeste são os mais diluídos, quimicamente mais homogêneos, com conteúdos muito similares de $\mathrm{K}, \mathrm{Na}$ e Ca (Tabela 1). Somente no rio Preto da Eva, o Mg ocorre $50 \%$ mais concentrado que o $\mathrm{Ca}$, enquanto no Urubu, mais a jusante (P8) e no igarapé Preto, o conteúdo desses dois cátions é similar, porém inferior ao $\mathrm{Ke} \mathrm{Na}$.

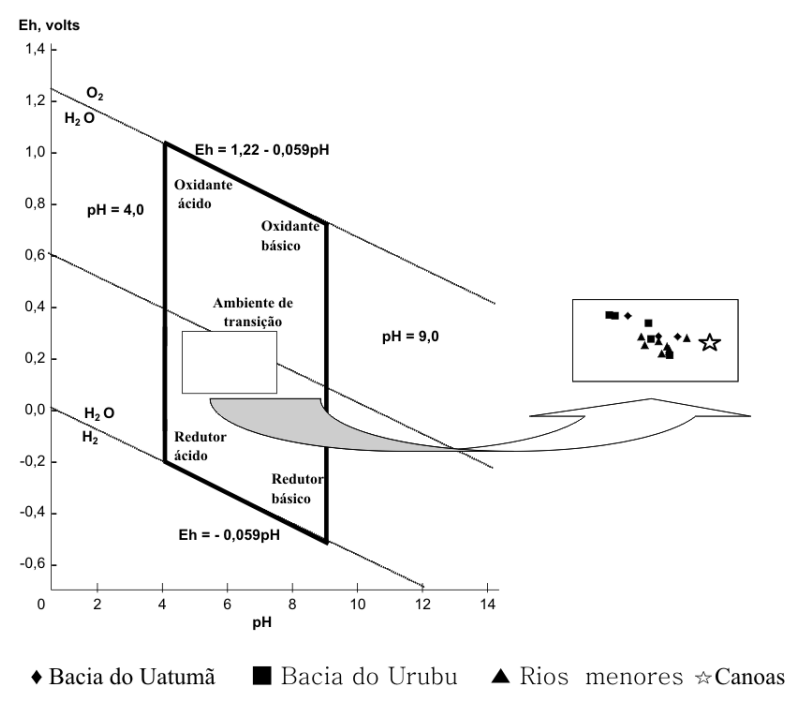

Figura 2 - Correlação entre os parâmetros de Eh e pH das águas estudadas com base no diagrama de Krauskopf (1972). 
Tabela 1 - Características químicas das água estudadas (Eh em mV, condutividade (cond.) em $\mu \mathrm{S} . \mathrm{cm}^{-1}$ e os íons em mg.L-1).

\begin{tabular}{|c|c|c|c|c|c|c|c|c|c|c|c|c|c|c|}
\hline Amostra & $\mathrm{pH}$ & Eh & Cond & K & $\mathrm{Na}$ & $\mathrm{Mg}$ & $\mathrm{Ca}$ & $\mathrm{Cl}$ & $\mathrm{SiO}_{2}$ & $\mathrm{~F}$ & $\mathrm{PO}_{4}$ & $\mathrm{Fe}$ & $\mathrm{Ni}$ & $\mathrm{Zn}$ \\
\hline 1- Coruja & 5,64 & 242 & 12,20 & 4,40 & 1,39 & 0,40 & 1,31 & 6,54 & 4,67 & 0,05 & 0,001 & 1,10 & 0,06 & 1,50 \\
\hline 2- Barreto & 4,76 & 331 & 18,20 & 1,55 & 0,34 & 0,41 & 0,60 & 2,18 & 1,65 & 0,01 & 0,007 & 1,40 & 0,08 & $<0,20$ \\
\hline 3- Uatumã & 5,30 & 243 & 12,40 & 0,77 & 0,68 & 0,38 & 2,07 & 2,18 & 2,79 & 0,02 & $<0,001$ & 0,70 & 0,13 & 0,60 \\
\hline 4- Canoas & 6,21 & 219 & 10,90 & 4,47 & 1,25 & 0,50 & 1,16 & 2,18 & 9,62 & 0,04 & 0,001 & 2,40 & 0,12 & $<0,20$ \\
\hline 5- Sta.Cruz & 5,13 & 299 & 15,70 & 1,08 & 0,41 & 0,12 & 0,28 & 4,36 & 2,41 & $<0,01$ & 0,002 & 0,60 & $<0,05$ & $<0,20$ \\
\hline 6- Urubuí & 4,54 & 331 & 19,80 & 0,63 & 0,47 & 0,19 & 0,33 & 2,18 & 2,04 & 0,01 & $<0,001$ & 1,30 & 0,12 & $<0,20$ \\
\hline 7- Urubu & 4,44 & 333 & 20,80 & 0,26 & 0,47 & $<0,01$ & 0,13 & 2,06 & 1,92 & 0,02 & 0,005 & 0,70 & 0,12 & $<0,20$ \\
\hline 8- Urubu & 5,50 & 162 & 6,80 & 0,90 & 0,47 & 0,06 & 0,04 & 1,82 & 1,16 & 0,05 & $<0,001$ & 0,20 & 0,15 & $<0,20$ \\
\hline 9- Preto & 5,17 & 231 & 8,70 & 0,25 & 0,57 & 0,06 & 0,04 & 2,06 & 0,04 & 0,02 & 0,001 & 0,80 & 0,10 & $<0,20$ \\
\hline 10- Preto da Eva & 5,48 & 177 & 8,20 & 1,51 & 0,62 & 0,24 & 0,13 & $<0,05$ & 1,70 & 0,04 & 0,002 & 2,10 & 0,15 & 1,30 \\
\hline 11- Tarumã Açu & 5,00 & 241 & 10,10 & 0,15 & na & na & 0,25 & 2,06 & 0,02 & $<0,01$ & 0,006 & na & 0,12 & $<0,20$ \\
\hline 12- Caru & 5,36 & 169 & 8,80 & 0,19 & 0,24 & 0,03 & 0,07 & $<0,05$ & 1,14 & 0,05 & 0,002 & 0,20 & 0,12 & $<0,20$ \\
\hline 13- Anebá & 5,45 & 199 & 7,90 & 0,25 & 0,20 & 0,04 & 0,33 & $<0,05$ & 1,16 & 0,02 & 0,004 & 0,20 & 0,06 & $<0,20$ \\
\hline 14- Treze & 5,49 & 188 & 8,00 & 0,16 & 0,20 & 0,01 & 0,22 & $<0,05$ & 1,58 & 0,02 & 0,005 & 0,10 & 0,12 & $<0,20$ \\
\hline 15- Sanabani & 5,06 & 206 & 8,60 & 0,23 & 0,23 & 0,04 & 0,04 & $<0,05$ & 1,58 & 0,01 & 0,004 & 0,20 & 0,10 & $<0,20$ \\
\hline 16- Itabani & 5,30 & 222 & 7,80 & 0,31 & 0,25 & 0,01 & 0,22 & 1,87 & 1,62 & 0,03 & 0,002 & 0,10 & 0,08 & $<0,20$ \\
\hline 17- Itapiranga & 5,80 & 235 & 9,40 & 0,36 & 0,32 & 0,04 & 0,22 & 3,63 & 1,04 & 0,02 & 0,002 & 0,10 & 0,20 & $<0,20$ \\
\hline Média & - & 237 & 11,43 & 1,03 & 0,51 & 0,17 & 0,44 & 2,76 & 2,13 & 0,03 & 0,002 & 0,76 & 0,11 & 1,13 \\
\hline Água preta ${ }^{1}$ & $4-6,3$ & & & $0,1-2,2$ & $0,1-2,9$ & $0,01-0,7$ & $0,01-4,5$ & $0,4-3,5$ & $4,2-6,9$ & & & $0,8-2,8$ & & \\
\hline CONAMA & & & & & & & & & & & & 0,30 & 0,25 & 0,18 \\
\hline
\end{tabular}

1 a 3 - Bacia do Uatumã; 5 a 8 - Bacia do Urubu; 9 a 17 - rios menores. Média calculada só com os valores acima do limite de detecção, na - não analisado, 1- média obtida dos dados de Sioli (1957), Santos et al. (1984), Santos e Ribeiro (1988), Konhauser et al. (1994) e Gaillardet et al. (1997).

Dentre os ânions analisados o $\mathrm{Cl}$ foi o mais abundante, exceto no Uatumã, Canoas, Preto da Eva, Caru, Anebá, Treze e Sanabani, onde o silício predomina. O conteúdo mais elevado de $\mathrm{Cl}$ nas bacias do Uatumã e Urubu pode ser conseqüência de estar associado, além da água da chuva, como normalmente ocorre nas águas da Amazônia (Gaillardet et al., 1997), também a minerais das rochas do Supergrupo Uatumã como apatita $\left(\mathrm{Ca}_{5}\left(\mathrm{PO}_{4}\right)_{3}(\mathrm{~F}, \mathrm{Cl}, \mathrm{OH})\right)$ que por ser instável no ambiente superficial (Oliveria e Imbernon, 1988) pode liberar $\mathrm{Cl}$ que é altamente móvel. Contudo, não se pode descartar um incipiente aporte antrôpico. O F e P têm teores bem menores que os demais ânions e não há diferenças significativas entre as bacias (Tabela1).

Considerando-se os rios maiores, Uatumã e Urubu, com dois (P1 e 2) e três (P5, 6 e 9) afluentes estudados, respectivamente, nota-se que para o primeiro há decréscimo de $\mathrm{K}$ e aumento de Ca no canal principal, enquanto no segundo $\mathrm{Ke} \mathrm{Mg}$ diminuem dos afluentes para o ponto mais a montante do Urubu (P7), enquanto $\mathrm{Na}$ e Ca têm variação irregular. $\mathrm{O}$ $\mathrm{Ca}, \mathrm{Cl}$ e $\mathrm{SiO}_{2}$ diminuem e $\mathrm{Na}$ se mantém constante do P7 para jusante do Urubu (P8). O Preto tem menor conteúdo de material dissolvido que Preto da Eva no qual deságua, exceto $\mathrm{Cl}$ (Tabela 1). Observa-se, portanto que não há relação direta entre a composição química da drenagem principal e os afluentes.

Dentre os elementos-traço analisados (Fe, $\mathrm{Zn}, \mathrm{Ni}, \mathrm{Co}$, $\mathrm{Mn}, \mathrm{Pb}, \mathrm{Cu}, \mathrm{Cr}, \mathrm{Li}, \mathrm{Cd}, \mathrm{Sr}$ e Mo), somente Fe, Zn e Ni apresentaram teores acima do limite de detecção (Tab. 1). $\mathrm{O}$ ferro é predominante sobre os demais (Tabela 1) e atinge valor máximo de 2,10 mg/L no rio Preto da Eva e 2,40 $\mathrm{mg} / \mathrm{L}$ no igarapé Canoas. Os teores menos expressivos estão nos rios menores, onde varia entre $0,1 \mathrm{mg} / \mathrm{L}$ e $0,2 \mathrm{mg} / \mathrm{L}$. $\mathrm{O} \mathrm{Ni}$ tem pequena variação entre as drenagens, de $<0,05$ $\mathrm{mg} / \mathrm{L}$ a $0,20 \mathrm{mg} / \mathrm{L}$ (Fig. 11), enquanto o Zn está abaixo do limite de detecção $(<0,2 \mathrm{mg} / \mathrm{L})$ na maior parte delas, exceto nos igarapés Coruja e Uatumã e no rio Preto da Eva, onde alcança, respectivamente, $1,5 \mathrm{mg} / \mathrm{L}, 0,6 \mathrm{mg} / \mathrm{L}$ e $1,3 \mathrm{mg} / \mathrm{L}$ (Tabela 1).

A condutividade elétrica (CE) é mais elevada nas drenagens do Uatumã e Urubu, com destaque para o Barreto, Urubuí e Urubu (P7), entre $18,2 \mu \mathrm{S} / \mathrm{cm}$ e $20,8 \mu \mathrm{S} / \mathrm{cm}$ (Tabela 1 ). Esses valores, que são a medida indireta da quantidade de íons dissolvidos presentes na água, indicam aporte de soluçôes mais concentradas em elementos solúveis, possivelmente em conseqüência das rochas ígneas por onde percolam (Fig.1). Como $\mathrm{SiO}_{2}$, K e Na são os íons com os teores mais elevados, 
Tabela 2 - Matriz de correlação entre os parâmetros analisados ( $\mathrm{F}^{\mathrm{PO}}{ }_{4}^{3}$, Zn e Ni apresentaram correlação $\left.\leq 0,5\right)$.

\begin{tabular}{|c|c|c|c|c|c|c|c|c|c|c|}
\hline & & Eh & CE & $\mathrm{Cl}^{-}$ & $\mathrm{SiO}_{2}$ & $\mathrm{Na}$ & $\mathrm{K}$ & $\mathrm{Mg}$ & $\mathrm{Ca}$ & $\mathrm{Fe}$ \\
\hline $\mathrm{pH}$ & 1,00 & $-0,46$ & 1,00 & $-0,62$ & 0,81 & 0,82 & 0,80 & 0,81 & 0,72 & 0,71 \\
\hline Eh & & 1,00 & $-0,47$ & $-0,57$ & $-0,46$ & $-0,41$ & $-0,45$ & $-0,49$ & $-0,42$ & $-0,43$ \\
\hline CE & & & 1,00 & 0,48 & 0,97 & 0,99 & 0,98 & 0,96 & 0,89 & 0,89 \\
\hline $\mathrm{Cl}$ & & & & 1,00 & $-0,42$ & $-0,46$ & $-0,42$ & $-0,57$ & $-0,34$ & $-0,30$ \\
\hline $\mathrm{SiO}_{2}$ & & & & & 1,00 & 0,96 & 1,00 & 0,93 & 0,96 & 0,92 \\
\hline $\mathrm{Na}$ & & & & & & 1,00 & 0,97 & 0,95 & 0,88 & 0,88 \\
\hline K & & & & & & & 1,00 & 0,94 & 0,94 & 0,91 \\
\hline $\mathrm{Mg}$ & & & & & & & & 1,00 & 0,89 & 0,87 \\
\hline $\mathrm{Ca}$ & & & & & & & & & 1,00 & 0,94 \\
\hline $\mathrm{Fe}$ & & & & & & & & & & 1,00 \\
\hline
\end{tabular}

são eles que mais contribuem para a condutividade elétrica nestas águas, o que é reforçado por terem as correlações elevadas entre si (Tabela 2). A condutividade também tem correlação com os demais elementos analisados, exceto $\mathrm{Cl}$ e Eh.

A variação nos teores e na proporção na ordem de grandeza dos íons reflete a heterogeneidade das águas pretas, contudo a composição química é compatível com a encontrada por Sioli (1957), Stallard e Edmund (1988), Santos et al. (1984), Santos e Ribeiro (1988), Konhauser et al. (1994), Gaillardet et al. (1997), Silva et al. (1999), Horbe et al. (2005), entre outros, ou seja, $\mathrm{Na}$ e K são mais concentrados que Ca e Mg. Quando comparados aos valores máximos permitidos (CONAMA 357/2005) constata-se que, apesar do ferro estar acima do permitido, assim como $\mathrm{Zn}$, especialmente nas drenagens do Uatumã e Urubu, as demais características estudadas indicam preservação de seus ambientes naturais. Esse fato é reforçado por manterem valores similares aos encontrados por Schmidt (1972) e Campos (1994).

\section{ANÁLISE MULTIVARIADA}

Com base nas cargas do primeiro fator da análise estatística multivariada por componentes principais, verificou-se que, das variáveis analisadas, somente $\mathrm{Eh}, \mathrm{Cl}$ e $\mathrm{F}$ apresentaram carga inferior a 0,60 (Tabela 3), ou seja, são as menos significativas para caracterizar as águas estudadas. Com base nas demais variáveis foram obtidos os escores das amostras (Figura 3).

As amostras estudadas se dispõem ao longo do eixo do fator 1 , de modo que as drenagens a sudeste, com cargas positivas nesse fator, formam um grupo que se situa no primeiro quadrante e somente o rio Tarumã-Açu, com escore negativo no fator 2, situa-se no quarto quadrante. O Uatumã, Canoas e Santa Cruz tem as cargas mais negativas no fator 1, de modo que situam-se mais a esquerda no eixo, enquanto o Urubu, Urubuí, Barreto e Preto, com cargas nesse fator entre - 0,51 e 0,45 , estão em posição intermediária entre os dois primeiros

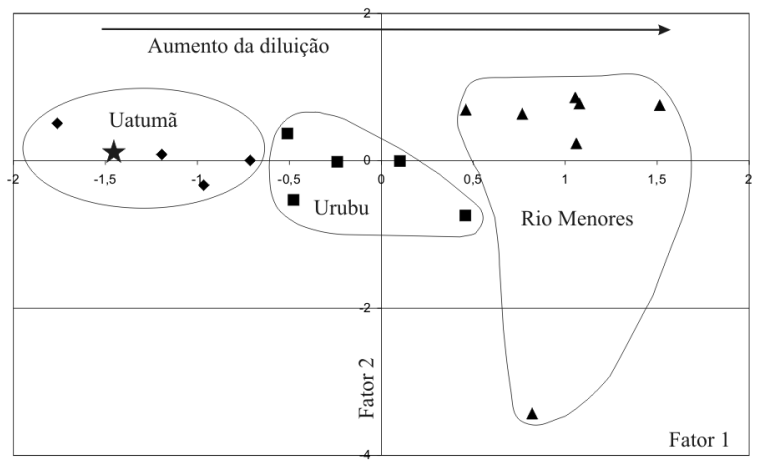

Figura 3: Diagrama da análise de componentes principais das águas estudadas ( - Drenagens do Uatumã, $\star$ - igarapé Coruja, $\mathbf{\square}$ - drenagens do Urubu, $\Delta$ - rios menores a sul sudeste).

Tabela 3 - Carga das variáveis nos fatores 1 e 2.

\begin{tabular}{lll}
\hline Variáveis & Fator 1 & Fator 2 \\
\hline $\mathrm{pH}$ & 0,87 & $-0,11$ \\
$\mathrm{Eh}$ & $-0,53$ & 0,32 \\
$\mathrm{CE}$ & 0,98 & $-0,05$ \\
$\mathrm{Cl}$ & $-0,55$ & 0,46 \\
$\mathrm{SiO}$ & 0,97 & 0,04 \\
$\mathrm{~F}$ & 0,32 & 0,52 \\
$\mathrm{Na}$ & 0,97 & $-0,04$ \\
$\mathrm{~K}$ & 0,98 & 0,01 \\
$\mathrm{Mg}$ & 0,07 & $-0,78$ \\
$\mathrm{Ca}$ & 0,92 & 0,12 \\
$\mathrm{Fe}$ & $-0,07$ & $-0,84$ \\
$\mathrm{Zn}$ & 0,27 & 0,76 \\
$\mathrm{Ni}$ & 0,23 & 0,68 \\
Variânça & $50 \%$ & $21 \%$ \\
\hline
\end{tabular}


grupos. O igarapé Coruja assemelha-se estatisticamente ao Uatumã e seus afluentes (Figura 3). Essa disposição caracteriza que, a medida que aumenta o valor do escore do fator 1 , as águas tornam-se mais diluídas, com decréscimo no conteúdo de álcalis, $\mathrm{HCO}_{3}, \mathrm{Cl} \mathrm{e} \mathrm{SiO}_{2}$. Assim, as drenagens mais a norte, sob maior influência das rochas ígneas, são as que têm maior conteúdo de elementos dissolvidos; as drenagens da bacia do Urubu, sob maior influência das rochas sedimentares das Formaçôes Prosperança, Nhamundá e Pitinga, têm conteúdo intermediário de elementos dissolvidos; enquanto as drenagens a sul-sudeste, que drenam exclusivamente a Formação Alter do Chão, são as mais diluídas.

\section{RELAÇÃO ENTRE A QUÍMICA DAS ÁGUAS E A LITOLOGIA}

Ao considerar que quartzo, caulinita e feldspato potássico são minerais abundantes nas rochas da região e, portanto, são a fonte de $\mathrm{K} \mathrm{e} \mathrm{SiO}_{2}$, o diagrama de estabilidade desses dois elementos a $25^{\circ} \mathrm{C}$ (Drever 1997) pode nos dar informaçōes sobre a relação de estabilidade das águas em relação ao ambiente geológico. O feldspato potássico gera caulinita por hidrólise durante o intemperismo, conforme a reação abaixo:

$$
\begin{gathered}
2 \mathrm{KAlSi}_{3} \mathrm{O}_{8(s)} \\
\text { feldspato }
\end{gathered}
$$

cuja constante de equilíbrio é: $\left.\left.\mathrm{K}_{\text {felds-caul }}=\right]_{4} \underline{\mathrm{H}}_{4} \underline{\mathrm{SiO}}_{4}\right]^{4}\left[\mathrm{~K}^{ \pm}\right]^{2}$

$\left[\mathrm{H}^{+}\right]^{2}$

A caulinita, sob condições de intenso intemperismo, forma gibbsita, de acordo com a reação abaixo:

$$
\underset{\text { caulinita }}{\mathrm{Al}_{2} \mathrm{Si}_{2} \mathrm{O}_{5}(\mathrm{OH})_{4(\mathrm{~s})}}+5 \mathrm{H}_{2} \mathrm{O}=2 \mathrm{Al}(\mathrm{OH})_{3(\mathrm{~s})}+2 \mathrm{H}_{4} \mathrm{SiO}_{4(\mathrm{aq})}
$$

cuja constante de equilíbrio é: Caul.-gibb. $=\left[\mathrm{H}_{4} \mathrm{SiO}_{4}\right]^{2}$

Essas equações mostram a relação direta entre a quantidade de feldspato e a concentração de potássio em solução, de modo que, sob condiçôes de intenso intemperismo, as águas tendem a ter mais $\mathrm{H}_{4} \mathrm{SiO}_{4}$ em detrimento da caulinita. Quando a composição das águas é lançada no diagrama log $\left(\left[\mathrm{K}^{+}\right] /\right.$ $\left[\mathrm{H}^{+}\right]$versus $\log \left[\mathrm{H}_{4} \mathrm{SiO}_{4}\right]$ (Figura 4), observa-se que, em sua maioria, estão em equilíbrio com a caulinita. Devido ao maior conteúdo em $\mathrm{Ke} \mathrm{SiO}_{2}$, os igarapés Coruja (P1) e Canoas (P4) estão próximos à linha de solubilidade do quartzo e do campo do feldspato potássico, o que é indicativo de maior contribuição desses minerais na composição química da água e supersaturação em $\mathrm{SiO}_{2}$. As demais drenagens, quimicamente mais diluídas, estão próximas ao limite caulinita/gibbsita, o que indica ambiente mais lixiviado, especialmente nos igarapés Preto (P9) e Tarumã-Açu (P11) em equilíbrio com a gibbsita. Constata-se, portanto a forte influencia litológica na composição química das águas, corroborando o observado por Stallard e Edmund (1988) para águas da Amazônia.

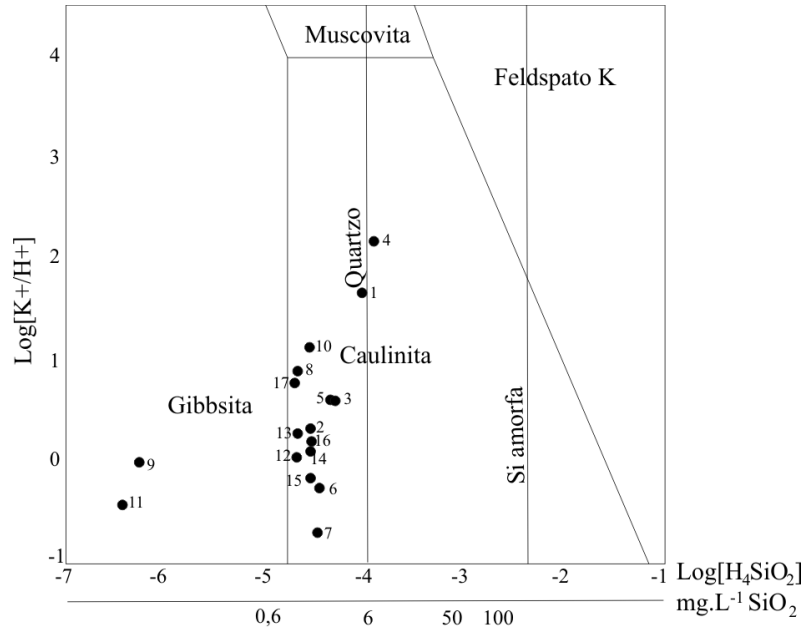

Figura 4 - Diagrama de estabilidade dos minerais em relação a composição química das águas estudadas a $25^{\circ} \mathrm{C}$ (a relação dos número está na tabela 1)

\section{CONCLUSÃO}

Este estudo demonstra que as águas pretas de pequenas drenagens localizadas no NE do Amazonas, apesar de serem de ambiente redutor ácido e com baixo conteúdo de elementos dissolvidos, são quimicamente heterogêneas e refletem o ambiente geológico por onde percolam. $\mathrm{SiO}_{2}, \mathrm{Na}$ e $\mathrm{K}$ são os constituintes mais abundantes na fase dissolvida. As menos diluídas são as drenagens mais a norte da região, correspondentes as bacias do Uatumã, Urubu e igarapé Canoas que drenam rochas da Suíte Intrusiva Água Branca e Mapuera, Grupo Iricoumé e as Formações Prosperança, Nhamundá, Manacapuru, Pitinga. Os rios menores, que correm para o rio Amazonas, sobre os sedimentos da Formação Alter do Chão, são os mais diluídos, enquanto o Tarumã-Açú, afluente do rio Negro e sobre o mesmo tipo de rocha, diferencia-se destes pelos teores bem mais baixos de $\mathrm{SiO}_{2}$. A forte diluição e as concentrações muito baixas de elementos-traços são típicas de ambiente intempérico em condiçôes tropicais úmidas onde há intensa e rápida percolação de água.

\section{AGRADECIMENTOS}

Os autores agradecem a Universidade Federal do Amazonas e a Companhia de Pesquisa de Recursos Minerais - Serviço Geológico do Brasil, pela infra-estrutura dos laboratórios e de campo e a CAPES, pela bolsa de mestrado do primeiro autor. Agradecem também as sugestôes dos revisores, que ajudaram a melhorar a qualidade do trabalho.

\section{BIBLIOGRAFIA CITADA}

Campos, Z. E. S. 1994. Parâmetros Físico-químicos em igarapés de água clara e preta ao longo da rodovia BR-174 entre Manaus e Presidente Figueiredo - AM. Dissertação de mestrado, Instituto Nacional de Pesquisa da Amazônia. 90pp. 
CONAMA 357/2005 In: http://www.mma.gov.br/port/conama

Cunha, H.B.; Simões, C.A. 2000. Caracterização físico-química das águas do Rio Negro e seus tributários. In. IX Jornada de Iniciação Científica. Anais. Manaus-AM. 325-329pp.

Cunha, P.R.C.; Gonzaga, F.G.; Coutinho, L.F.C., Feijó, F.J., 1984. Bacia do Amazonas. Bol. Geoc. Petrobras, 8:47-55.

Drever, J.I. 1997. The Geochemistry of Natural Waters Surface and Groundwater Environments. Prentice Hall. 460pp.

Gaillardet, J.; Dupré, B.; Allègre, C. J.; Négrel P. 1997, Chemical and physical denudation in the Amazon River Basin. Chemical Geology 142, 141-173.

Horbe, A.M.C.; Gomes, I.L.F.; Miranda, S.A.F.; Silva, M.S.R. 2005. Contribuição à hidroquímica de drenagens no Município de Manaus - AM. Acta Amazônica 35:119-124.

Konhauser, K. O.; Fyfe, W. S.; Kronberg, B. I., 1994, Multi-element chemistry of some Amazonian waters and soils. Chemical Geology 111: $155-175$.

Krauskopf, K. B. 1972. Introdução a Geoquímica. Ed. da USP. Volume 1, 197-214.

Lopes, U. B. 1992. Aspectos Físicos, Quimicos e Ecológicos das misturas naturais de águas físico-quimicamente diferentes, na Amazônia. INPA-Pós-graduação em Ciências Biológicas. Tese de doutorado, 49pp.

Nimer, E.1991. Clima. Geografia do Brasil - Região Norte. IBGE. Rio de Janeiro, v.3, 61- 67pp.

Oliveria, S.M.B. e Imbernon, R.A.L. 1998. Weathering alteration and related REE concentration in the Catalão I carbonatite complex, central Brazil. Journal of South American Earth Science, 4, 379-388

Radambrasil 1978. Folha SA.20. Geologia, geomorfologia, pedologia, vegetação e uso potencial da terra. 626pp.

Santos, J.O., Souza, M.M., Prazeres, W.V., Silva, L. S., Barreto, E.L., Pessoa, M.R. 1974. Projeto Norte da Amazônia - Dominio Baixo Rio Negro, Geologia da folha SA.20-X. Vol.II A. Convênio DNPM-CPRM. 238pp.
Santos, U. M.; Bringel S. R. B.; Bergamin F. H.; Ribeiro M. N. G.; Bananeira, M. 1984. Rios da Bacia Amazônica I - Afluentes do Rio Negro. Acta Amazônica, 14 (1-2), 222-237.

Santos, U. M.; Ribeiro, M. N. G. 1988. A Hidroquímica do rio Solimões-AM. Acta Amazônica, 18 (3-4): 145-172.

Schmidt, G.W. 1972. Chemical properties of some water in the tropical rain forest region of central Amazonia along the new road Manaus-Caracaraí. Amazoniana 3:199-207.

Schobbenhaus, C.; Campos, D. A.; Derze, G. R.; Asmus, H. E. 1984. Geologia do Brasil. DNPM. 86-87p.

Silva, M.S.R.; Ramos, J.P.; Pinto, A.G..N. 1999. Metais de transição nos sedimentos de igarapés de Manaus-AM. Acta Limnologica Brasiliensis, 11:89-100.

Sioli, H. 1957. Valores de pH de águas Amazônicas. Boletim do museu paraense Emilio Goeldi. Geologia 1: 1-35.

Sioli, H. 1965. A limnologia e a sua importância em pesquisas da Amazônia. Amazoniana, I: 11-35.

Stallard, R. F.; Edmond, J.M. 1988, Geochemistry of the Amazon 2. The influence of the geology and weathering environment on the dissolved load. Journal of the Geophysical Research 388 9671-9688.

Standard methods for the examination of water and wastewater (1998). Prepared and published jointly by American Public Health Association APHA, 19th edition.

Valério, C.; Souza, V.S.; Macambira, M.J.B.; Galarza, M.A. 2006. Geoquímica e geocronologia $\mathrm{Pb}-\mathrm{Pb}$ em zircão da Suite Intrusiva Água Branca, Município de Presidente Figueiredo (AM): evidências de colisão no Paleoproterozóico da Amazônia Ocidental. Revista Brasileira de Geociências 36:359-370.

Veiga, J.P.J.; Nunes, A.C.B.; Souza, E.C.; Santos, J.O.S.; Amaral, J.E., Pessoa, M.R.; Cruz, S.A.S. 1979. Projeto Sulfetos do Uatumã. Parte I. Vol. I A . Convênio DNPM-CPRM. 345p.

Recebido em 29/11/2007

Aceito em 01/09/2008 
